\title{
Calibration of Land Surface Model Using Remotely Sensed Evapotranspiration and Soil Moisture Predictions
}

\author{
$\underline{\text { A. Kunnath Poovakka }}{ }^{a}$, D. Ryu ${ }^{\text {a }}$, L. J. Renzullo ${ }^{\text {, R. Pipunic }}{ }^{a}$, and B. George ${ }^{\text {a }}$ \\ ${ }^{a}$ Department of Infrastructure Engineering, The University of Melbourne, Parkville, Victoria,3010. \\ ${ }^{b}$ CSIRO Land and Water, P.O. Box 1666, Canberra, ACT 2601, Australia \\ Email: kunnath@,student.unimelb.edu.au
}

\begin{abstract}
Calibration is the process of estimating the optimal parameters for a model to accurately reflect the real system, using historical records of system data. The model calibration, however, is frequently limited by availability, quality, quantity and the nature of the ground observations. Lack of streamflow observations in the vast majority of the world, for example, constrains the calibration of hydrologic and land surface models. In this study, an attempt is made to calibrate a land surface model by using satellite retrievals of soil moisture and evapotranspiration (ET), without relying on streamflow measurements. This paper examines the capability of using satellite measurements for the calibration of hydrologic/land surface models for ungauged locations.
\end{abstract}

The Australian Water Resources Assessment Landscape model (AWRA-L) modified to have single hydrological response unit (HRU) per each grid cell is chosen, as a simple land surface model that requires minimum forcing variables. Initial parameters for the control case are generated based on the fraction of trees and the Budyko's dryness index. Microwave soil moisture retrievals from the Advanced Microwave Scanning Radiometer-EOS (AMSR-E) and daily estimates of ET from the Moderate Resolution Imaging Spectroradiometer (MODIS) are adopted to calibrate a selection of the AWRA-L parameters. Shuffled complex evolution uncertainty algorithm (SCE-UA) is employed to perform local calibration at 25-km grid cell in the Kyeamba catchment, southeastern Australia.

Multiple criteria objective function for calibration is selected based on the AWRA-L output behavior of evapotranspiration and soil moisture compared to respective remote measurements. It considers the bias and the correlation between observed and simulated evapotranspiration and the correlation between observed and simulated soil moisture. Calibration experiments are carried out in daily time step from 2003 to 2007 and validated from 2008 to 2010 . The optimum parameters obtained are employed to calculate the monthly average runoff ratio and is evaluated against the runoff ratio derived from streamflow observations at Kyeamba catchment.

The results show that the calibration of AWRA-L using remotely sensed evapotranspiration and soil moisture can improve the predictions of evapotranspiration and runoff. Validation conducted in a separate period also exhibit improvements in the prediction of evapotranspiration, whereas the improvement in soil moisture is trivial during both calibration and validation periods. The monthly runoff ratio estimated after calibration is improved compared to the runoff ratio in the control case. This indicates the potential of calibration with evapotranspiration and soil moisture in improving streamflow predictions. Further research is warranted to increase efficiency in prediction of runoff ratio, so that the calibration scheme can be applied in the regions with sparse or no gauging stations.

Keywords: Australian Water Resources Assessment Landscape model (AWRA-L), evapotranspiration (ET), soil moisture, calibration, validation, runoff ratio 


\section{INTRODUCTION}

A typical model gives only an approximate description of the real system. It is the process of calibration, which estimates the best fit parameters for a model to accurately reflect the components of a real system, using historical records of system data (Duan et al., 1992). Similarities between the observed and modeled variables are judged by the objective functions used (Wagener and Wheater, 2006). The success of calibration depends largely upon the quality, nature and amount of monitoring data.

Streamflow is the most common output of interest in hydrological modeling since it contains time-integrated information about water in the catchment system. Streamflow is also a key component of water resource management and its extreme values are associated with natural disasters such as floods and drought (Duan et al., 1992; Gupta, et al., 2005). Calibration of hydrologic/land surface model is carried out usually using streamflow and, if available, other hydrological variables (e.g., Zhang et al., 2011). However, lack of streamflow observations and other ground data in the vast majority of areas makes calibration of hydrological model a difficult task (Wagener and Montanari, 2011). The most common approach used for calibrating ungauged modelling is parameter regionalization (Wagener and Wheater, 2006). However, regionalization may fail to provide catchment specific parameters at ungauged catchments due to the unique nature of the watersheds. Grid based models are generally not calibrated; instead they employ parameters available from soil maps, remotely sensed vegetation, land surface map, etc. In this paper, an attempt has been made to calibrate a grid based land surface model using remotely sensed evapotranspiration and soil moisture data to explore methods to calibrate hydrological models without streamflow observations.

Land surface models, which are used to model interactions between land, atmosphere and vegetation were developed from the early simple Penman evaporation model (Manabe and Bryan, 1969) and later to more complex soil vegetation atmospheric transfer (SVAT) models, such as SiB (Simple Biosphere Model) (Sellers et al., 1996), SimSphere (Gillies and Carlson, 1995) and Community Land Model (CLM) (Oleson et al., 2004). Among existing land surface models, Australian Water Resources Assessment system Landscape model (AWRA-L) developed by the Commonwealth Scientific and Industrial Research Organisation (CSIRO) and the Australian Bureau of Meteorology (BoM) is chosen due to the following merits. AWRA-L is a relatively simple lumped model requiring minimal input forcing variables. It was developed as a gridbased model that calculates the water flows and stores at the land surface. The calibration of AWRA-L has been, however, confined to limited number of catchments where streamflow records and input forcing data are available. Therefore, it is crucial to develop schemes to calibrate the model using alternative sets of observations, for example, satellite-based land surface variables, for the parts of Australia where ground data are sparse.

In this study, MODIS retrievals of evapotranspiration (ET) and AMSR-E soil moisture data are used to calibrate AWRA-L in 2003-2007. A separate set of observations in 2008-2010 is used for evaluation. Shuffled complex evolution uncertainty algorithm (SCE-UA) developed by Duan et al., (1992) is implemented to perform local calibration at a grid cell with a resolution $25-\mathrm{km}$ in Kyeamba catchment area, southeastern Australia. This study has important implications for the use of remotely sensed evapotranspiration and soil moisture to implement hydrological models at catchments with sparse or no monitoring stations.

\section{MATERIALS AND METHODS}

\subsection{AWRA-L}

AWRA-L is a grid-based one dimensional biophysical model which calculates the flows and stores of water at the land surface on a daily time step (Peña Arancibia et al., 2011; Van Dijk, 2010). The original AWRA-L version 0.5 is run at $5-\mathrm{km}$ resolution with multiple hydrological response units (HRUs) for each grid cell, however, it is modified to run at $25 \mathrm{~km}$-by-25 km grid size with a single HRU in order to match the support scale of the microwave soil moisture retrievals available for the study period. The main advantage of the model over other land surface models is that it requires minimal forcing variables to generate the output streamflow, evapotranspiration and soil moisture. The input forcing variables of the model are daily precipitation, daily minimum and maximum temperature values and solar radiation. The model consists of three unsaturated soil layers, a ground water store and a separate routing water store where surface and subsurface runoffs join. In AWRA-L, the lateral distribution of water between the grid cells is ignored when it is run in grid-based mode. This constraint limits not only the prediction of stream discharge from large catchments in the grid-based mode but also the catchment-based application of this model if the catchment size is smaller than $25 \mathrm{~km}$ by $25 \mathrm{~km}$. 
In the original AWRA-L, each grid cell can have more than one HRU. For the current application, the model is modified to have only one HRU per grid cell in order to simplify the parameterization at each grid cell. Parameters such as groundwater drainage coefficient and drainage fraction at filled capacity are calculated using Budyko's dryness index, which is the ratio of mean precipitation and mean potential evapotranspiration. Landcover specific parameters for HRU are chosen based on the fraction of tree coverage. If the tree fraction is greater than $50 \%$ of the HRU, its vegetation cover is considered a deep-rooted vegetation, otherwise as shallow-rooted vegetation. AWRA-L model has 36 parameters, among which, 32 are HRU-specific parameters.

In this study, $11 \mathrm{HRU}$ specific parameters are selected for calibration (Table 1). The calibration parameters are adopted based on the results from variance-based Sobol's sensitivity analysis (Sobol, 1993), in which the total variance of model response is decomposed to provide relative contributions made by individual parameters and parameter interactions. Initial values are chosen randomly within the bounds of the parameters for the 'before calibration' model runs.

Table 1: Calibration parameters and their range

\begin{tabular}{|c|c|c|c|}
\hline Parameter & Description & Unit & Range \\
\hline$\beta$ & Coefficient describing rate of hydraulic conductivity increase with water content & - & $1-14$ \\
\hline$F_{\text {sEmax }}$ & Soil evaporation scaling factor when soil water supply is not limiting evaporation & - & $0.2-1$ \\
\hline$h$ & Height of the vegetation & $\mathrm{m}$ & $0.1-50$ \\
\hline$U_{D 0}$ & Maximum root water uptake rates from deep soil & $\mathrm{mm} \mathrm{d}^{-1}$ & $1-7$ \\
\hline$U_{S 0}$ & Maximum root water uptake rates from shallow soil & $\mathrm{mm} \mathrm{d}^{-1}$ & $1-7$ \\
\hline$t_{\text {grow }}$ & Characteristic time scale for vegetation growth towards equilibrium & days & $20-1000$ \\
\hline$t_{\text {senesce }}$ & Characteristic time scale for vegetation senescence towards equilibrium & days & $10-200$ \\
\hline$S_{\text {leaf }}$ & Specific canopy rainfall storage capacity per unit leaf area & $\mathrm{mm}$ & $0.03-0.8$ \\
\hline$V_{C}$ & Vegetation photosynthetic capacity index per unit canopy cover & - & $0.05-1$ \\
\hline FdrainFC_scale & Factor to scale $F d r a i n F C$ (drainage fraction at field capacity) & - & $0.2-5$ \\
\hline FdrainFC_shape & Factor to scale FdrainFC & - & $0.2-5$ \\
\hline
\end{tabular}

\subsection{Data}

Daily time series of precipitation, minimum and maximum temperature and solar radiation from January 2003 to December 2010 derived from AWAP (Australian Water Availability Project) are used as input forcing. AWAP is developed by CSIRO Marine and Atmospheric Research (CMAR), BoM and the Bureau of Rural Science (BRS) and it is monitoring the state and trend of terrestrial water balance over Australia (http://www.csiro.au) using gauge based data. The original AWAP data at a resolution of $0.05^{0} \times 0.05^{0}$ are aggregated to the model grid scale $0.25^{0} \times 0.25^{0}$.

For calibrating AWRA-L, daily estimates of actual evapotranspiration derived from the surface reflectance of MODIS-Terra satellite (Guerschman et al., 2009) and microwave soil moisture retrievals from C and X bands of Advanced Microwave Scanning Radiometer-EOS (AMSR-E) version 5.0 (Su et al., 2013) are used. ET data derived from MOD43B4 product of Terra sensor are available from January 2001 to December 2010. The satellite ET, originally at a resolution of $0.05^{0} \times 0.05^{0}(\sim 5 \mathrm{~km} \times 5 \mathrm{~km})$ over Australia, is rescaled to $0.25^{0} \times 0.25^{0}$ for the current study. AMSR-E soil moisture represents the volumetric water content of the top 1-2 $\mathrm{cm}$ of the soil at a resolution of $0.25^{0} \times 0.25^{0}$. AMSR-E data from 2002 to 2011 are used for calibration. Additionally, daily in-situ records of streamflow over the study catchment from January 2003 to December 2007 are used for evaluation of the calibration scheme.

\subsection{Model Calibration and Validation}

Instead of using streamflow for calibration, the present study uses satellite retrievals of evapotranspiration and microwave soil moisture. The objective function (OBF) is constructed based on the comparison of the model derived and satellite estimated evapotranspiration in terms of bias and correlation (see Eq. 1). Since the remotely sensed and simulated soil moisture is not in the same measurement scale, correlation between them is considered: 


$$
O B F=E D+5 *|\ln (1+B)|^{2.5}+\left(1-R_{E}^{2}\right)+\left(1-R_{S M}^{2}\right),
$$

where $B$ is the Bias, which is the ratio of total model error between the observed and simulated ET and total observed ET (Zhang et al., 2011). $R_{E}$ and $R_{S M}$ are the correlation coefficients for evapotranspiration and soil moisture respectively:

In equation 1, ED is the Euclidian distance from the ideal point, which is the core of Kling Gupta Efficiency (KGE) developed from the decomposition of Nash Sutcliffe efficiency (NSE, Gupta et al., 2009). Decomposition of NSE in to different components can help to understand the model performance and can give better results during calibration with highly seasonal variables. $E D$ computes the Euclidian distance of its three components, $\gamma, \alpha$ and $\beta$, from the optimal point as:

$$
E D=\sqrt{(\gamma-1)^{2}+(\alpha-1)^{2}+(\beta-1)^{2}},
$$

where $\alpha=\frac{\sigma_{s}}{\sigma_{0}}$ and $\beta=\frac{\mu_{s}}{\mu_{o}}$. $\sigma_{o}$ and $\sigma_{s}$ are the standard deviations of observed and simulated evapotranspiration, respectively, while $\mu_{o}$ and $\mu_{s}$ stand for the mean of observed and simulated ET. $\alpha$ describes the relative variability between the observed and simulated evapotranspiration, $\gamma$ represents the correlation between the observed and simulated evapotranspiration and $\beta$ is the ratio between the mean of modeled and observed ET, which accounts for bias. $E D=0$ defines the exact concurrence between the observed and modeled data.

Multi-objective SCE-UA global optimization method is used to derive the optimal parameters of AWRA-L. The calibration is conducted for a grid at Kyeamba catchment. The latitude and longitude of the centroid of the selected grid cell is $-35.375^{\circ}$ and $147.625^{\circ}$, respectively. The tree fraction of the grid cell is 0.25 , so parameter values corresponding to 'shallow rooted vegetation' are used. Eleven parameters shown in Table 1 are calibrated for the period from 2003 to 2007 and validated from 2008 to 2010.

In order to avoid the need of routing surface and subsurface runoffs, monthly average of simulated (gridspecific) AWRA-L discharge is converted to the runoff ratio and it is evaluated against the observed runoff ratio generated from the observed discharge. AWAP precipitation is used for determining both observed and simulated runoff ratio. For the comparison of AWRA-L and AMSR-E soil moisture, since they are not measuring the same vertical thickness and contain various biases, observed soil moisture is rescaled using linear regression to the model space for evaluating the calibrated model output.

\section{RESULTS AND DISCUSSIONS}

The aim of this study is to analyse the effect of calibration of AWRA-L model with remotely sensed evapotranspiration and top soil moisture on prediction of ET, soil moisture and stream flow. The calibration parameters are chosen based on their sensitivity towards evapotranspiration, soil moisture and streamflow.

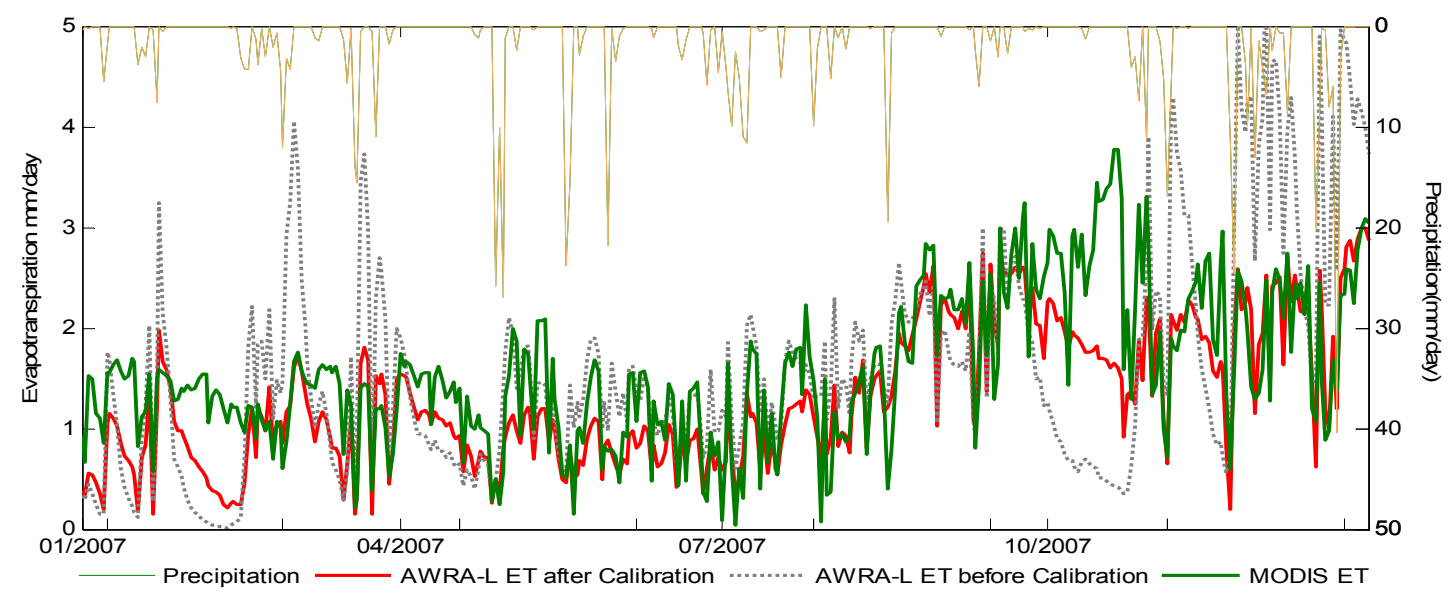

Figure 1: Comparison of AWRA-L evapotranspiration before and after calibration with MODIS evapotranspiration

The simulated results of evapotranspiration after calibration show a good agreement with the MODIS evapotranspiration (Figure 1). Linear correlation coefficient of ET has increased from 0.63 to 0.85 after calibration. The comparison between the simulated and MODIS ET is illustrated in Figure 1 for the year 
2007. Simulated ET after calibration is negatively biased during this period, which experienced a long period of low rainfall, whereas it is positively biased during period of heavy rainfall. However, compared to the model output of ET before calibration, RMSD (Root Mean Square Deviation) of ET has reduced from 0.95 to 0.54 after calibration.

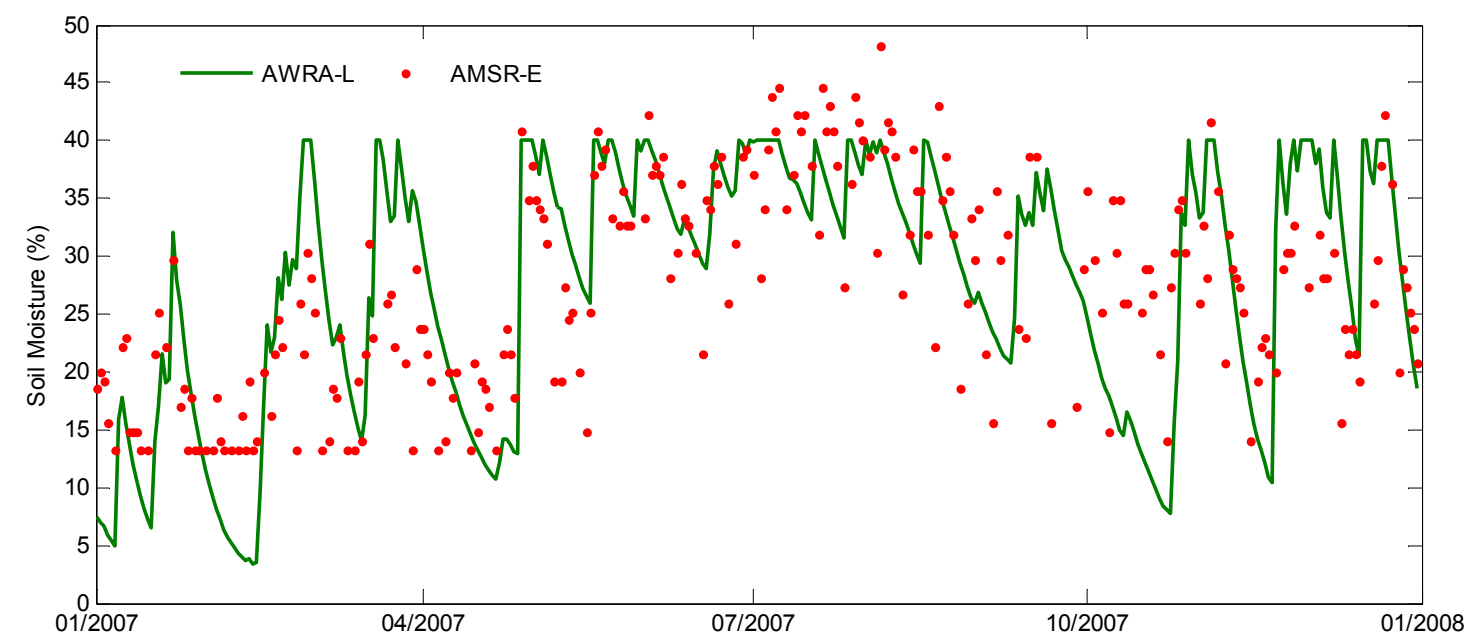

Figure 2: Comparison of AWRA-L volumetric soil moisture after calibration with AMSR-E soil moisture

The modeled upper layer soil moisture content after calibration is converted into volumetric soil moisture by assuming a field capacity of $40 \%$. Since observed and simulated soil moisture is not in the same definition, observed soil moisture is rescaled to the model space for evaluation (Figure 2). After calibrating the model the correlation coefficient has shown negligible difference, it infers the passiveness of soil moisture in determining the model calibration. The bias between the observed and simulated soil moisture is not examined, due to the difference in the scale of measurement. The reason for poor simulation at the lower values of soil moisture is likely because of the model soil moisture simulates the upper $5-15 \mathrm{~cm}$ and is compared with the AMSR-E soil moisture estimated from the upper 1-2 cm of the soil layer.

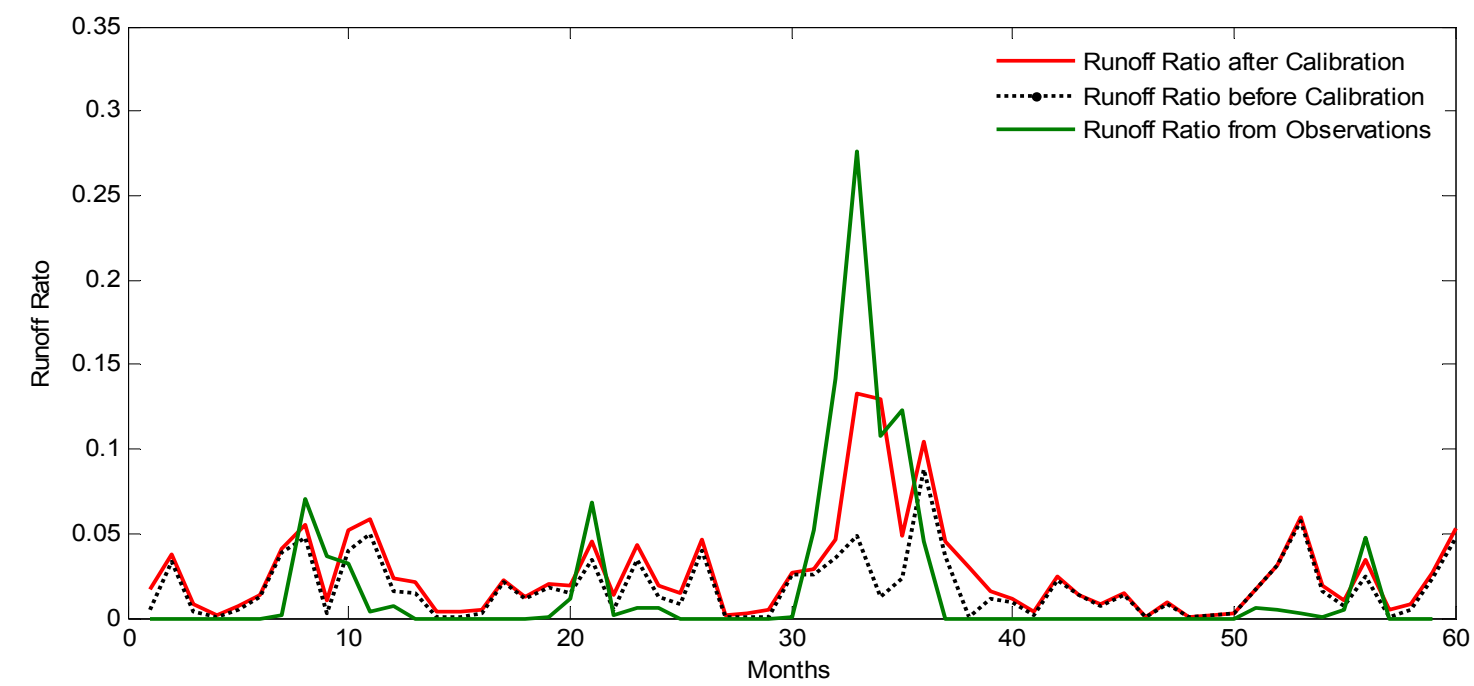

Figure 3: Evaluation of AWRA-L runoff ratio before and after calibration with runoff ratio derived from streamflow observations

The optimum set of parameters obtained after calibration is then incorporated into the model to generate daily discharge. The monthly averaged discharge and monthly averaged AWAP precipitation is used to calculate the monthly averaged runoff ratio. Runoff ratio estimated using the calibrated parameters has improved compared to the runoff ratio estimated using prior parameters with a decrease in RMSD from 0.042 to 0.033. Compared to runoff ratio calculated from observed stream flow, model is overestimating the runoff ratio except for the peak flow periods. Initial model estimates of runoff ratio and calibrated model estimates are almost similar in all other periods except the peak flow period. During peak flows the calibrated model shows 
improved predictions of runoff ratio. This improvement in runoff ratio after calibration infers the capability of the calibration to improve the prediction of streamflow. Evapotranspiration, soil moisture and discharge are the components of model water balance, so improvement in evapotranspiration will improve the streamflow.

Validation experiments are done from 2008 to 2010 using the optimum set of parameters. The results gave a

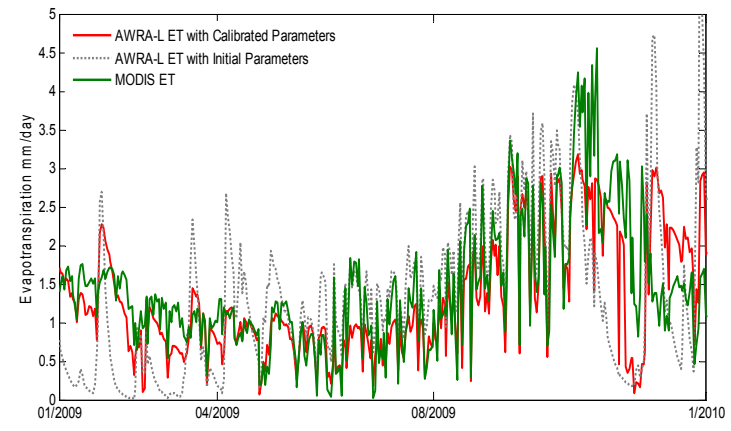

Figure 4: Comparison of AWRA-L evapotranspiration with MODIS evapotranspiration in validation period

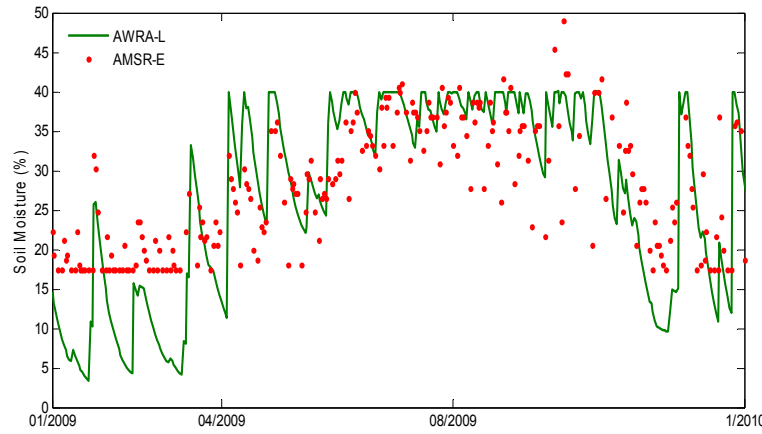

Figure 5: Comparison of AWRA-L soil moisture with AMSR-E soil moisture in validation period

good concurrence between the remotely sensed and simulated evapotranspiration (Figure 4) and correlation has shown good improvement (Table 1). The satisfactory results during the validation period exhibit effectiveness of attained optimal parameters. Modelled soil moisture during validation period shows a little improvement in correlation with AMSR-E soil moisture (Figure 5, Table 1).

Table 1 summarizes the results of calibration and validation for evapotranspiration, soil moisture and runoff ratio. The calibration with ET and soil moisture has increased the efficiency in prediction of evapotranspiration, whereas, soil moisture did not change considerably with calibration. Monthly runoff ratio predictions are improved after calibration. The study is done in only one $25 \mathrm{~km}$ grid cell in Kyeamba catchment region and evaluated against the streamflow records available for that area. Further study should be done to ensure a better prediction of runoff.

Table 2: Statistics of evapotranspiration and soil moisture before and after calibration and validation

\begin{tabular}{|c|c|c|c|c|}
\hline \multirow{2}{*}{ Statistics } & $\begin{array}{c}\text { Initial } \\
\text { Parameters }\end{array}$ & $\begin{array}{c}\text { Optimum } \\
\text { Parameters }\end{array}$ & $\begin{array}{c}\text { Initial } \\
\text { Parameters }\end{array}$ & $\begin{array}{c}\text { Optimum } \\
\text { Parameters }\end{array}$ \\
\cline { 2 - 5 } & \multicolumn{2}{|c|}{ Calibration } & \multicolumn{2}{c|}{ Validation } \\
\hline Correlation Coefficient (RE) -ET & 0.637 & 0.851 & 0.585 & 0.805 \\
\hline Correlation Coefficient (R) - SM & 0.776 & 0.773 & 0.718 & 0.741 \\
\hline RMSD - ET & 0.956 & 0.540 & 1.032 & 0.630 \\
\hline RMSD - Runoff Ratio & 0.042 & 0.033 & & \\
\hline
\end{tabular}

\section{CONCLUSIONS}

This study investigates the potential of remotely sensed observations in the calibration of hydrologic/ land surface models. MODIS retrievals of evapotranspiration and microwave AMSR-E soil moisture are used to calibrate the AWRA-L model. The optimum parameter set obtained is able to give good estimate of ET during both calibration and validation period. Top layer soil moisture showed little sensitivity to calibration. Calibration with ET and soil moisture improved the predictions of runoff ratio and that illustrates ability of the proposed calibration scheme in predicting streamflow.

This is the first study done in our knowledge, using only satellite retrievals of evapotranspiration and soil moisture for calibrating AWRA-L model. More study need to be done to increase the efficiency of streamflow prediction with the same calibration scheme using only remotely sensed measurements. Ultimate focus of this research is to reduce uncertainty in predictions at ungauged locations by calibration of the model with remotely sensed measurements. 


\section{ACKNOWLEDGMENTS}

This research is supported by International Postgraduate Research Scholarships (IPRS), Australian Postgraduate Awards (APA) and the Carlton Connect Initiatives Fund - Research Collaboration Project of The University of Melbourne.

\section{REFERENCES}

Duan, Qingyun, Soroosh Sorooshian, and Vijai Gupta (1992). Effective and efficient global optimization for conceptual rainfall-runoff models. Water Resources Research, 28 (4), 1015-1031.

Gillies, R. R., and T. N. Carlson (1995). Thermal remote sensing of surface soil water content with partial vegetation cover for incorporation into climate models. Journal of Applied Meteorology, 34(4), 745-756.

Gupta, Hoshin V, Keith J Beven, and Thorsten Wagener (2005). Model calibration and uncertainty estimation. Encyclopedia of hydrological sciences.

Gupta, Hoshin V., Harald Kling, Koray K. Yilmaz, and Guillermo F. Martinez (2009). Decomposition of the mean squared error and NSE performance criteria: Implications for improving hydrological modelling. Journal of Hydrology, 377 (1-2), 80-91.

Guerschman, J. P., A. I. J. M. Van Dijk, G. Mattersdorf, J. Beringer, L. B. Hutley, R. Leuning, R. C. Pipunic, and B. S. Sherman (2009). Scaling of potential evapotranspiration with MODIS data reproduces flux observations and catchment water balance observations across Australia. Journal of Hydrology, 369(1-2), 107-119.

Manabe, S., and K. Bryan (1969). Climate Calculations with a Combined Ocean-Atmosphere Model. Journal of the Atmospheric Sciences, 26(4), 786-789.

Oleson, K. W., Y. Dai, G. Bonan, M. Bosilovich, R. Dickinson, P. Dirmeyer, F. Hoffman, P. Houser, S. Levis, and G.-Y. Niu (2004). Technical description of the community land model (CLM). NCAR Tech. Note NCAR/TN-461+ STR, 173.

Peña Arancibia, J.L, A.I.J.M Van Dijk, M.P Stenson, J Anthony, and N.R Viney (2011). Opportunities to evaluate a landscape hydrological model (AWRA-L) using global data sets. In International Congress on Modelling and Simulation, 4071-4077. Perth, Australia.

Sellers, P. J., C. J. Tucker, G. J. Collatz, S. O. Los, C. O. Justice, D. A. Dazlich, and D. A. Randall (1996). A Revised Land Surface Parameterization (SiB2) for Atmospheric GCMS. Part II: The Generation of Global Fields of Terrestrial Biophysical Parameters from Satellite Data. Journal of Climate, 9(4), 706-737.

Sobol', I. M. (1993), Sensitivity Estimates for Nonlinear Mathematical Models, Math. Model. Comput. Exp., $1,407-417$.

Su, C.-H., D. Ryu, R. I. Young, A. W. Western, and W. Wagner (2013). Inter-comparison of microwave satellite soil moisture retrievals over the Murrumbidgee Basin, southeast Australia. Remote Sensing of Environment, 134(0), 1-11.

Van Dijk, A. I. J. M. (2010). The Australian Water Resources Assessment System. Technical Report 3. Landscape Model (version 0.5) Technical Description. CSIRO: Water for a Healthy Country National Research Flagship.

Wagener, Thorsten, and Alberto Montanari (2011). Convergence of approaches toward reducing uncertainty in predictions in ungauged basins. Water Resources Research, 47 (6).

Wagener, Thorsten, and Howard S. Wheater (2006). Parameter estimation and regionalization for continuous rainfall-runoff models including uncertainty. Journal of Hydrology, 320 (1-2), 132-154.

Zhang, Y., N. Viney, F. Chiew, A. Van Dijk, and Y. Liu (2011). Improving hydrological and vegetation modelling using regional model calibration schemes together with remote sensing data. Proceedings of the 19th International Congress on Modelling and Simulation MODSIM2011 